\title{
Development of Op-Amp Based Piezoelectric Rectifier for Low Power Energy Harvesting Applications
}

\author{
Muhamad Syazmie Bin Sepeeh ${ }^{1}$, Farahiyah Binti Mustafa ${ }^{1 *}$, Anis Maisarah Binti Mohd Asry ${ }^{1}$, Sy Yi Sim ${ }^{1}$, Mastura \\ Shafinaz Binti Zainal Abidin ${ }^{2}$ \\ ${ }^{1}$ Department of Electrical Engineering Technology, Faculty of Engineering Technology, Universiti Tun Hussein Onn Malaysia, 86400 \\ Parit Raja, Batu Pahat, Johor, Malaysia \\ ${ }^{2}$ Department of Electronic and Computer Engineering, Faculty of Electrical Engineering, Universiti Teknologi Malaysia, 81310 \\ Skudai, Johor, Malaysia
}

\begin{abstract}
In this study, the development of operational amplifier (op-amp) based rectifier for piezoelectric energy harvesting applications was studied. The two stage op-amp full wave rectifier was used to convert the AC signal to DC signal voltage received by piezoelectric devices. The inverted half wave rectifier integrated with full wave rectifier were designed and simulated using MultiSIM software. The circuit was then fabricated onto a printed circuit board (PCB), using standard fabrication process. The achievement of this rectifier was able to boost up the maximum voltage of $5 \mathrm{~V}$ for input voltage of $800 \mathrm{mV}$. The output of the rectifier was in DC signal after the rectification by the op-amp. In term of power, the power dissipation was reduced consequently the waste power decreases. Future work includes optimization of the rectifying circuit to operate more efficiently can be made to increase the efficiency of the devices.
\end{abstract}

\section{Introduction}

Energy harvesting is a process that captures small amounts of energy that would otherwise be lost as heat, light, sound, vibration and movement. Piezoelectric energy harvesting, has been investigated since the late 1990s [1]. Energy harvesting technology has ability to create autonomous, self-powered electronic systems that do not rely on battery power for their operation [2]. There are available energy from the environment that allow self-sufficient energy to supply to low power consumption load such as sensor or radio transmitters. This available energy needs to convert before being used. The kinetic energy converts to electrical energy by using the piezoelectric device (PD) as a transducer.

In order to convert kinetic energy to electrical energy, some vibration or shocks need to apply on the surface of piezoelectric devices, then it will mechanically deform the piezoelectric crystal with tension or pressure to generate electrical charges. The electrical charges that being generated can measure as voltage. The circuitry of the energy harvesting connected to the piezoelectric devices by using the operational amplifier (op-amp) based rectifier to amplify the output and give the better desired output to the system.

The power dissipation will reduce as the waste power decreases. The rectifier used to convert the alternating current signal voltage to direct current signal voltage. It connected with the piezoelectric devices as a source energy, then flow through the rectifier. Based on the piezoelectric device, it is capabl e to generate AC signal from the vibration or movement that being apply on it. The AC signal from piezoelectric device converts to DC signal using rectifier.

In order to maximize the power transfer of the transducer to the load, rectifier will be the most important part in the piezoelectric energy harvesting. A recent method of rectifier used comparator-based active diode, but it faces oscillation problem and dc offset. This problem cause the lower power efficiency of the rectifier [3]. In this paper the rectifier used the active diodes based on op-amp. The reason for using the op-amp rectifier compared to other rectifier because it reduces the power dissipation and increase the power efficiency.

In this study, the design and development of op-amp based rectifier for low power energy harvesting applications reported. The rectifier simulated using MultiSIM software and the characterization carried out in order to check capability of the circuit to work as energy harvesting circuit.

\section{Research Method}

In this study, two stage op-amps full wave rectifier circuit has been proposed to convert the AC signal to DC signal. Figure 1 shows the schematic circuit and printed circuit board (PCB) of Op-amp based rectifier.

For negative input voltage, the output first Opamp should be positive, then the $D_{1}$ ON and $D_{2}$ OFF. Since, action of the first Op-amp is forcing the input

\footnotetext{
* Corresponding author: farahiyah@uthm.edu.my
} 
voltage of the Op-amp to the same level, the output is hold at the ground potential when the $D_{l}$ is ON. For positive input signal $V_{i}$, the output goes negative, the $D_{2}$ is ON and $D_{l}$ is OFF. The output of first Op-amp then acts as inverting amplifier. The gain set to 1 by $R_{2} / R_{I}$ which means $R_{2}=R_{I}$. The output of first Op-amp is $0 \mathrm{~V}$ follow the negative half cycle of the input for positive half cycle. This output becomes one of the input for the second Op-amp which summed with input waveform. At the first stage it has 2 relative gains to the input which means $R_{3}=2 R_{4}$

For second stage, at negative half cycle, the input wave summed with potential ground result the output of second Op-amp is a positive gain. The inverted wave of the half wave rectifier summed with input waveform and the gain of the half wave rectifier of first Op-amp for the positive half cycle results the positive output. The summer performs as an inverted again giving $V_{o}=\left|V_{i}\right|$ as shown in Figure 2 and Figure 5. The result is a full wave rectifier. Typically the gain of the half wave rectifier is set to 1 which are $R_{2}=R_{1}$ and ratio of $R_{3}$ and $R_{4}$ should be 1:2 so the summing of the input with the output of the half wave rectifier output will be sum up correctly. The light emitting diode (LED) used as a load in this rectifier circuit.

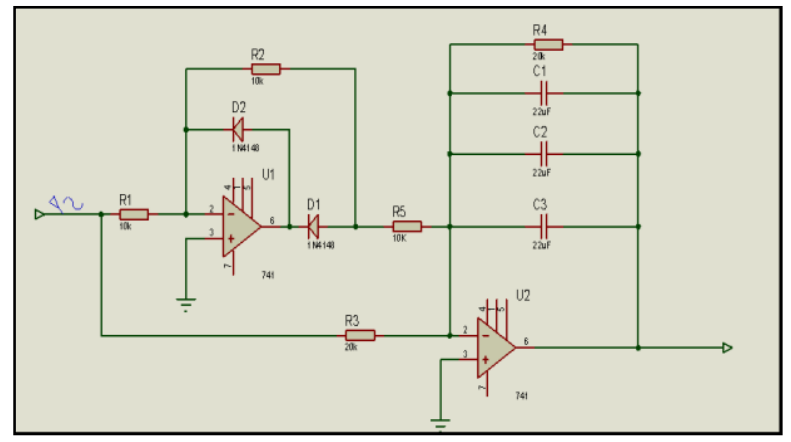

(a)

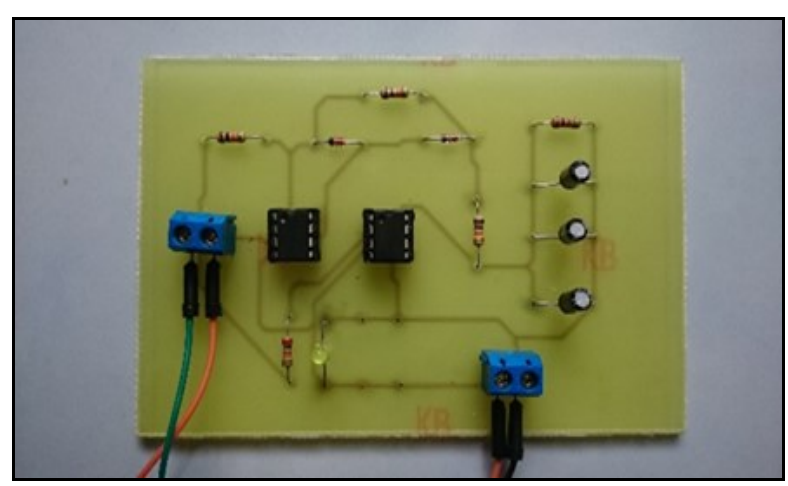

(b)

Fig 1. (a) Schematic and (b) PCB of op-amp based rectifier circuit.

\section{Result and Discussions}

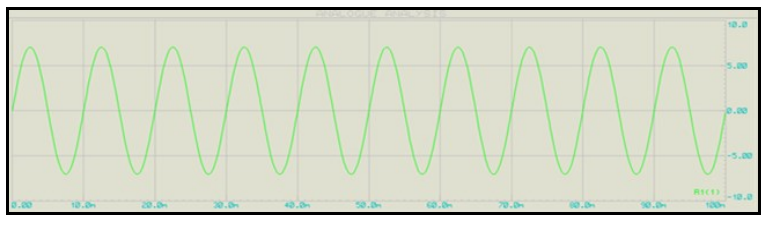

(a)

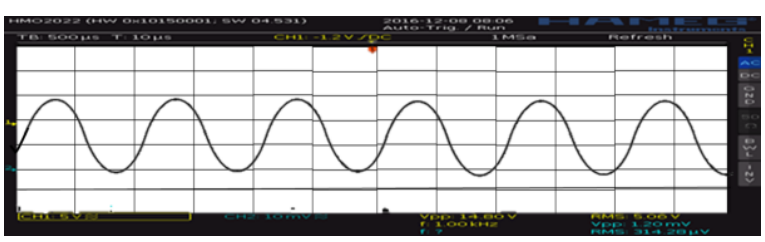

(b)

Fig 2. a) The simulation and b) experimental input waveform of the Op-amp based rectifier.

Based on the arrangement of the circuit, the input $V_{r m s}$ set at $5 \mathrm{~V}$ at the source of the circuit. The gain of the inverting op-amp is 1 . As shown in Figure 2 the amplitude of $V_{r m s}$ output is $5 \mathrm{~V}$. There are no different between the simulation and experimental.

$$
A_{V}=-\frac{R_{2}}{R_{1}}=\frac{10 \mathrm{k} \Omega}{10 \mathrm{k} \Omega}=-1
$$

By calculation the value of $\mathrm{V}_{\text {out }}$ :

$$
\begin{gathered}
A_{V}=\frac{V_{\text {out }}}{V_{\text {in }}} \\
1=\frac{V_{\text {out }}}{V_{\text {in }}}
\end{gathered}
$$

$$
\therefore V_{\text {out }}=5 \mathrm{~V}
$$

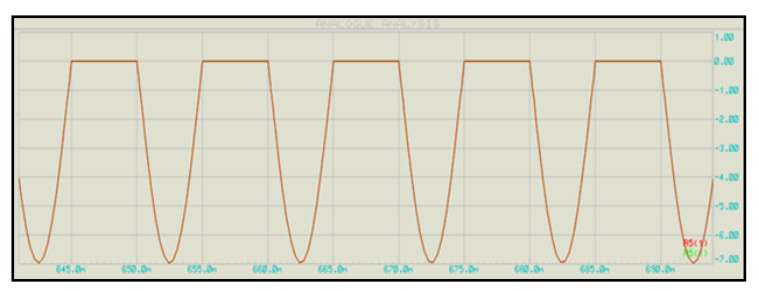

(a)

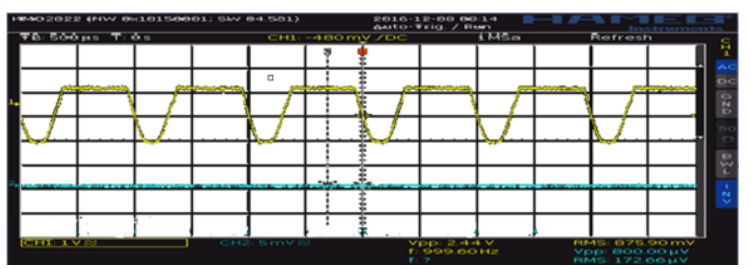

(b)

Fig 3. a) The simulation and b) experimental inverted halfwave rectified waveform of output by first Op-amp. 
Since inverting Op-amp used, the output waveform inverted as the output of the first stage of Op-amp is half wave. During the negative half-cycle of a sinewave input, the output should positive. During the positive half-cycle, the output should zero. The circuit that accomplishes this amazing feats looks like the inverting amplifier with a couple of diodes added because only one actually does the rectifying action.

The other simply keeps the Op-amp in control while the signal output holds at zero. For the positive half-cycle input, the Op-amp output goes negative forcing $D_{2}$ to turn $\mathrm{ON}$ and $D_{1}$ to shut OFF. The output sits at $0 \mathrm{~V}$. This is because the Op-amp still does its job of holding $V$ - at $0 \mathrm{~V}$ and because there is no current through $R_{2}$ and get $V_{o}=V$ - $=0 \mathrm{~V}$. The only thing left to reckon with is the current running through $R_{l}$ :

$$
I=\frac{V_{i}}{R_{2}}=\frac{1}{10 k}=0.5 m A
$$

During this half-cycle, the Op-amp's output swings negative to turn on $D_{l}$ enough to pull $0.5 \mathrm{~mA}$ through the diode.

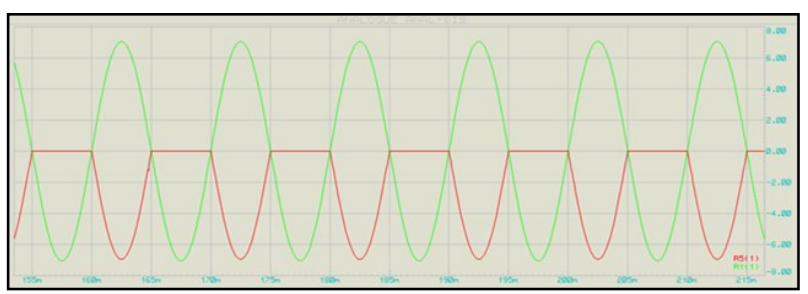

(a)

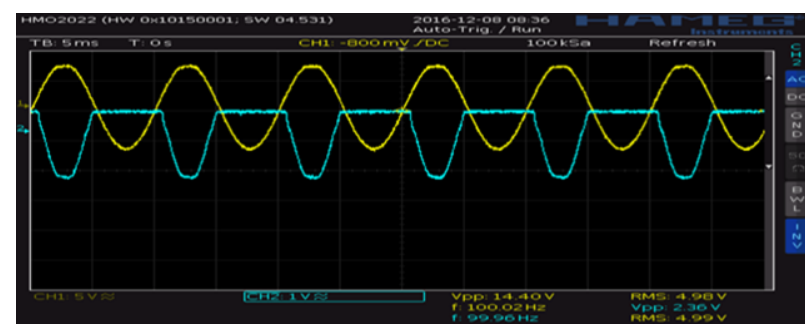

(b)

Fig 4. a) The simulation and b) experimental inverted halfwave with the input waveform.

As shown in Figure 4. The amplitude of the $V_{r m s}$ is $5 \mathrm{~V}$ that equal to the $V_{p-p}=7.07 \mathrm{~V}$ due to the gain of the operational amplifier.

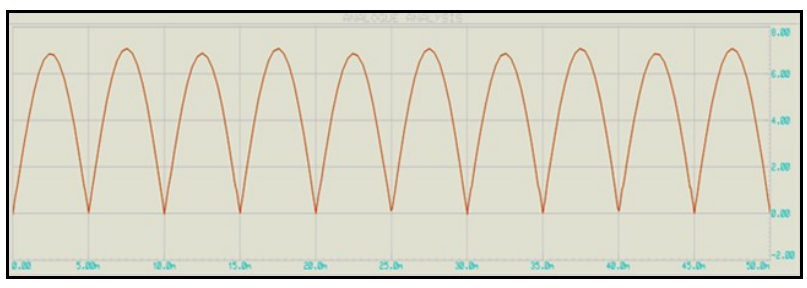

(a)

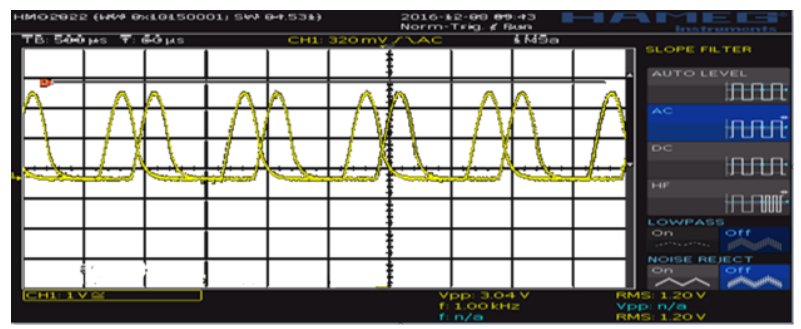

(b)

Fig 5. a) The simulation and b) experimental Full Wave rectified waveform of output by second Op-amp.

Two separate circuits used for each half of the full $\mathrm{AC}$ cycle and combined signal used to get the full wave rectified output [4]. From Figure 5, the output waveform generated by the second Op-amp. The output voltage $V_{\text {out }}$ form the second Op-amp are $7.07 V_{p-p}$ that equivalent to $5 \mathrm{~V}$ of $V_{r m s}$. There are different in phase shift when compared between the simulation and experimental.

$$
V_{\text {out }}=-R_{f}\left[\left(\frac{V_{\text {in } 1}}{R_{5}}\right)+\left(\frac{V_{\text {in } 2}}{R_{3}}\right)\right]
$$

$$
V_{\text {out }}=-20 k \Omega\left[\left(\frac{1.05 \mathrm{mV}}{10 \mathrm{k} \Omega}\right)+\left(\frac{7.07 \mathrm{~V}}{20 \mathrm{k} \Omega}\right)\right]-7.07 \mathrm{~V}
$$

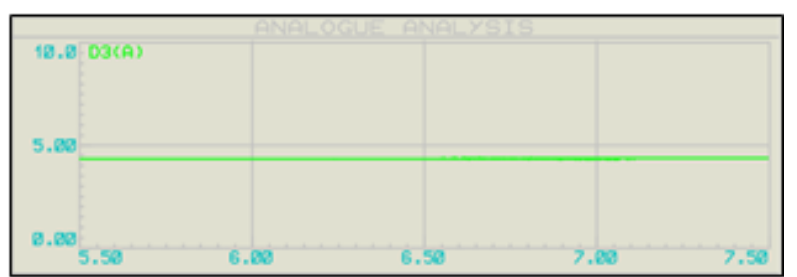

(a)

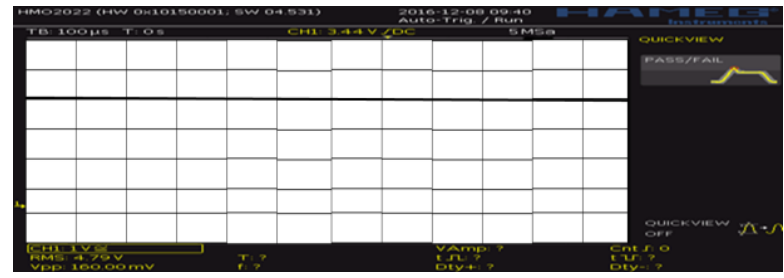

(b)

Fig 6. a) The simulation and b) experimental output of Opamp based rectifier. 
The output of Op-amp in Figure 6 rectified by $22 \mathrm{uF}$ capacitor filter. 3 units of capacitor used to rectify the peak of the full wave. As the input and current was $1.05 \mathrm{~mA}$ and $1.0 \mathrm{~mA}$ respectively, the $V_{p-p}$ of the rectified waveform is:

$$
\begin{aligned}
& V_{P+}+V_{P-}=V_{P-P} \\
& 4.90+4.79=9.69 \mathrm{~V}
\end{aligned}
$$

The $\mathrm{V}_{\mathrm{p}}$ of the waveform:

$$
\frac{V_{P+}+V_{P-}}{2}=4.845 \mathrm{~V}
$$

The $\mathrm{V}_{\mathrm{DC}}$ of the waveform:

$$
\frac{4.90 \mathrm{~V}+4.79 \mathrm{~V}}{2}=4.845 \mathrm{~V}
$$

Therefore, the efficiency of rectifier:

$$
\begin{gathered}
\text { Efficiency, } \eta=\frac{P_{\text {out } D C}}{P_{\text {in } A C}} \times 100 \% \\
P_{\text {out } D C}=V_{\text {out } D C} \times I_{\text {out } D C} \\
P_{\text {out } D C}=(4.845 \mathrm{~V} \times 1 \mathrm{~mA})=4.845 \mathrm{mV} \\
P_{\text {in } A C}=V_{\text {rms }} \times I_{\text {rms }} \\
P_{\text {in AC }}=(5 \mathrm{~V} \times 1.05 \mathrm{~mA})=5.25 \mathrm{~mW} \\
\text { Efficiency, } \eta=\frac{4.845 \mathrm{mV}}{5.25 \mathrm{mV}} \times 100 \%
\end{gathered}
$$

The output DC voltage of the Op-amp based rectifier is $4.845 \mathrm{~V}$. Compare to the simulation output is $4.35 \mathrm{~V}$. The voltage dropped through the circuit since LED used as the load of the circuit design.

Table 1 shows the comparison between this proposed method and previous proposed method. The input voltage for proposed design is $5 \mathrm{~V}$ in $\mathrm{AC}$ and the voltage output is $4.845 \mathrm{~V}$ in DC measured. The proposed design was using the full wave rectifier based on op-amp with the capacitor filter and achieved the highest power efficient of $92.28 \%$. Although the proposed method also used the operational amplifier as a rectifier but with some modification made, it achieved the highest value of voltage output in DC, power output in DC and power efficiency.

Table 1. Comparison with previous rectifier method

\begin{tabular}{|l|c|c|c|c|}
\hline Parameter & $\begin{array}{c}\text { Lam } \\
\text { Rectifier }\end{array}$ & $\begin{array}{l}\text { Synchronized } \\
\text { Switching } \\
\text { Rectifier }\end{array}$ & $\begin{array}{c}\text { A Self- } \\
\text { Powered } \\
\text { High- } \\
\text { Efficiency } \\
\text { Rectifier }\end{array}$ & $\begin{array}{c}\text { Proposed } \\
\text { Method }\end{array}$ \\
\hline $\begin{array}{l}\text { VoutDC } \\
(\mathrm{V})\end{array}$ & 2.78 & 1.8 & 2.9 & 4.845 \\
\hline $\begin{array}{l}\text { PoutDC } \\
(\mathrm{mW})\end{array}$ & 0.081 & 0.143 & 0.090 & 4.854 \\
\hline $\begin{array}{l}\eta \\
(\%)\end{array}$ & 90.00 & 77.00 & 91.20 & 92.28 \\
\hline
\end{tabular}

\section{Conclusion}

In this paper, the development of Op-amp based rectifier circuit has been present. The design circuit utilizes two of Op-amps with the capacitor filter through precise in rectification of the waveform. The configuration gives the advantages of precise rectification over a wide range of operating frequencies, a high input impedance and the ability to give the less power dissipation. An improved rectifier circuit employing the principles similar from the previous research.

\section{References}

1. S. Bhalla, S. Moharana, N. Kaur, V. Talakokula, Piezoelectric Materials, (John Wiley \& Sons, London, 2016)

2. M.N. Gupta, S.K. Yadav, Suman, AEEE, 4, 313 (2014) 
3. T. Gunasheela, E.K .Sharmitha, K. Senthilprakash, An Efficient Rectifier Design for Piezo Electric Energy Harvesting System (ICSEIE, Erode, 2015)

4. R. Dixit, C. K. Dwivedi, IJETAE, 4, 388 (2014)

5. Y. Sun, N. H. Hieu, C.J. Jeong, S.G. Lee, IEEE Trans. Power Electron. 27, 623 (2012)

6. X. D. Do, H. H. Nguyen, S.K. Han, D. S. Ha, S.G. Lee, JSTS, 15, 319 (2015)

7. X. D. Do, H. H. Nguyen, S.K. Han, D. S. Ha, S.G. Lee, IEEE Trans. Very Large Scale Integr. (VLSI) Syst. 23, 444 (2015) 